\title{
The Chaplin collection DVDs
}

\author{
By Jan Uhde
}

Spring 2004 Issue of KINEMA

Not surprisingly, more than two dozen Chaplin titles have already been published on DVD. Their quality is, like the weather, variable. The 2003 publication of the massive two-volume The Chaplin Collection by MK2 (the prodigious French producer Marin Karmitz) and Warner Brothers, is what film lovers have been waiting for: a virtually complete collection of Chaplin's features (only the 1967 A Countess from Hong Kong is not included) on a high-quality digital transfer from the Chaplin family film vault.

Chaplin enthusiasts will be happy to savour also the elusive "silent" 1925 version of The Gold Rush published with the 1942 sound-added version, in which Chaplin replaced the intertitles with his own voice-over commentary - one of the few professional mistakes of the great master's long career. The Chaplin Revue disc samples seven of his short classics, including A Dog's Life, Shoulder Arms, and Pay Day.

The plethora of added-on material includes Richard Schickel's 132-minute documentary Charlie: The Life and Times of Charles Chaplin (2003) with contributions from a pleiad of famous film personalities; a few home movies from the archives of Lord Mountbatten, numerous documentaries, newsreels, photos, and much more.

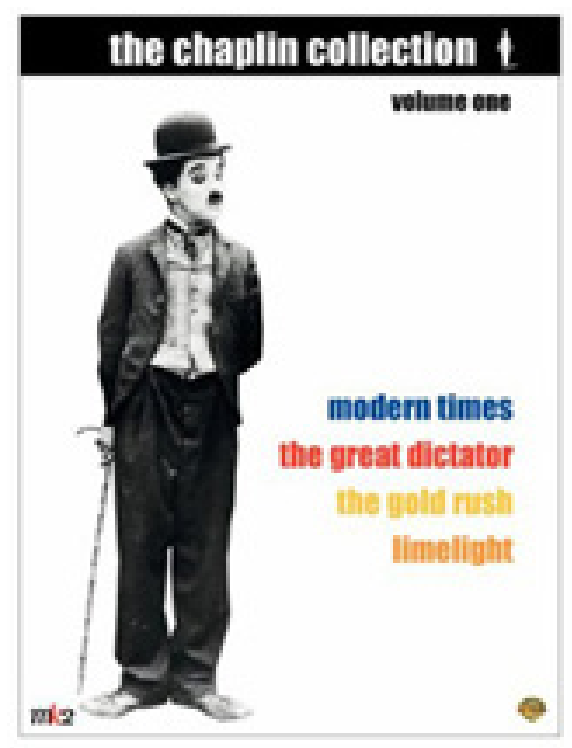

Figure 1: THE CHAPLIN COLLECTION vol. 1 \& 2 (20 DVDs) I NTSC, Reg. 1 9 MK2 S.A. and Warner Brothers, 2003 ฯ USD 189.84 (list, both volumes) I Available individually. Discounts

\section{Author Information}

Jan UHDE is Professor Emer. (Film Studies) at the University of Waterloo, Ontario, Canada. Born in Brno, Czech Republic. Graduated (MA) from the Faculty of Arts, Masaryk University, Brno; PhD received at the University of Waterloo, Ontario, Canada. He taught at the University of Waterloo (1970-2012) where he founded a General and Honours BA program in Film Studies at the Department of Fine Arts.

Publications: Latent Images: Film in Singapore Second edition, with Yvonne Ng Uhde (Ridge Books, National University Press of Singapore, 2010); Latent Images: Film in Singapore, with Yvonne Ng Uhde (Oxford University Press, 2000); Latent Images: Film in Singapore CD-ROM (2003, co-author); Vision and Persistence: Twenty Years of the Ontario Film Institute (University of Waterloo Press, 1990) and Ontario Film 


\section{the chaplin collection $\mathbf{t}$}

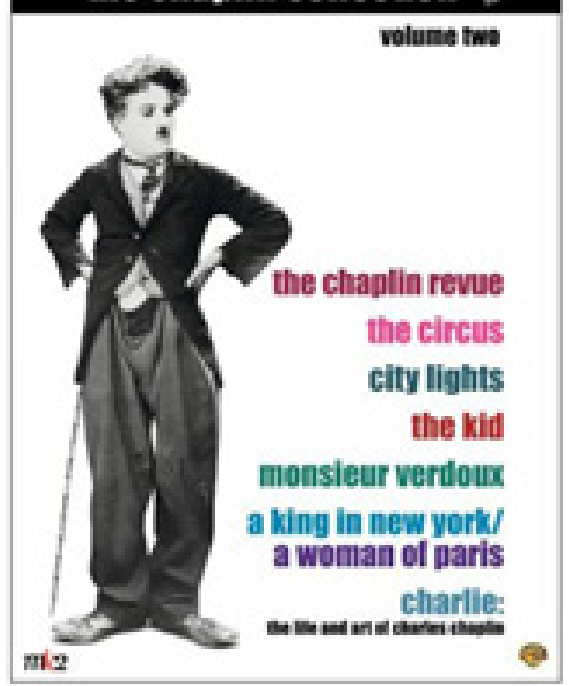

Figure 2:

Institute Programming Activities Index 1969-1989 (Toronto: Ontario Science Centre, 1990). He co-edited the Place in Space: Human Culture in Landscape (Proceedings from the Second International Conference of the Working Group "Culture and Landscape" of the International Association of Landscape Ecology, Pudoc Scientific Publishers, Wageningen, Holland, 1993). Jan Uhde has published articles and reviews in several countries (including Canada, USA, Germany, Italy), participated in international juries at film festivals and presented papers at international conferences in North America and Europe. In 1998/99, he was a visiting researcher at the School for Film and Media Studies, Ngee Ann Polytechnic, Singapore.

His professional and research interests focus on Singapore cinema; the identification and distancing mechanisms of the film viewer; the non-authored modifications and manipulation of films; and specific aspects of film history, including the Central European cinema.

He founded KINEMA in 1993. 